\title{
LA FORMACIÓN JURÍDICA DEL ARCIPRESTE DE TALAVERA
}

Hay en la obra del Arcipreste de Talavera interesantes aspectos juridicos. El tema no ha sido tratado hasta ahora en forma expresa. Sólo cabe destacar alguna que otra observación a nivel de manual o las notas a pic de página puestas por los editores al tratar de localizar las obras canónicas que cita el Arcipreste. $\mathrm{Y}$ cso es todo' ${ }^{1}$. Merece la pena llamar la atcnción sobre el tema.

No es sólo cuestión de citas de canonistas y obras de derecho. El Arcipreste de Talavera ha procurado recoger datos muy diversos del mundo jurídico. Definiciones, "exemplos», algún proceso que se imagina, reflexiones sobre la justicia o el derecho. $Y$ lo que es mucho más importante: toda una serie de datos procedentes de su propia experiencia personal. En ló que a esto último se refiere, no hay nada parecido en los escritores de la época.

Claro está que el Arcipreste no escribe sobre derecho en plan sistemático. No es un jurista que intenta sentar doctrina. Los datos van surgiendo aquí y allá a lo largo de su obra. El va a lo suyo, que es, como se sabe, poner al descubierto los peligros del amor y de la afición a las

1 Ios aspectos juridlicos-procesales del Corvacho har sido agudamente destacados por NICETO ALCALA-ZAMORA, en un artículo referente a diversos autores de nuestra literatura, Nuevas estampas procesales de la literatura española, en Revista de Derecho procesal iberoamericano, 1969, 2, pp. 321-27.

Entre las ediciones recientes del Corvacho -obra que hoy se prefiere desiguar dircctamente con el nombre del autor- destacan: Coriacho o Reprobación del anor mundano, ed. prólogo y notas de MLARTIN DE RIQUER. Barcelona, 1942; Alfionso Martífez DE Torido, Arcipreste de Talavera, ed. Mario Penna. Torino, 195I; AIronso MARTINI:Z DE Tor.IDO, Arcipreste de Talavera, ed. J. GonzAIIIZ MUiti, M. Maclrid, 1970. Haremos las citas por esta últin'a edición que lleva bibliografia en pp. 33-4. 
miljeres ${ }^{1}$. Un tema que, en principio, no parece muy adecuado para planteamientos jurídicos. Mas nuestro Arcipreste sabe ingeniárselas para probar sus conocimicntos en la materia.

En lo relativo a su expericucia personal, tiene muchas cosas que cont.ar de las mujeres. Sabe que, por satisfacer sus pasiones, son capaces da cometer gravísimos delitos, llevándose a los hombres tras de sí. Muertes, nutilaciones y engaños. A título de ejemplo nos ofrecerá pequeños relatos de delitos en los que participan mujeres. No sin antes advertir que su información es de primera mano: "Yo la vi»; "e yo fablé con ella». $A$ veces las cosas que cuenta son tan crudas, que se ve obligado a insistir en las fuentes de su información: "Vi más en la dicha ciudad de Tortosa, por ojo, dos cosas muy fuertes de creer, pero ipor Dios yo la vilı ${ }^{2}$. Se da el caso de que alguna de las víctimas llegará a morir en los brazos del buen Arcipreste. Su información, pues, no pudo ser mejor.

Ya se comprende que, con tal género de información, se acumulen los detalles. Iil acento está puesto en la forma de cometer el delito. Lin ocasioncs, hasta se reproducen las frases cruzadas entre los personajes al tiempo de delinquir. Todo esto presta más realismo a la narración. El Arcipreste procura trazar un cuadro lo más preciso posible. No se olvidan los nombres de los delincuentes, ni los lugares donde ocurrieron los hechos, situados todos ellos en tierras de la Corona de Aragón.

Desde el punto de vista jurídico, interesa más que la conducta del delincuente la forma de caśigar los delitos la autoridad judicial. En este punto, los datos son también valiosos. Una mujer que consiente la muerte de su hijo, causada por el amante, es llevada a la hoguera. Los hechos ocurricron en Tortosa ${ }^{3}$.

In la horca, en cambio, mucre a manos de la justicia otra mujer que, junto con su amante, roba y luego da muerte a su padre. El suceso tuvo lugar en Valeucia. Scría largo de contar, nos advierte el Arcipreste, "cómo fue sentenciada». Con todo, el resumen que hace es de gran interés. La mujer fue presa. Nuestro Arcipreste habló en la cárcel con la mujer y se interesó por su situación, tal como nos dice expresamente:

1 Desde esta perspectiva, como es sabido, ha sido estudiada la obra. Falta un estudio moderno y de conjunto sobre el papel de la mujer en la literatura castellana de la Baja Edad Media, para el que existe, un gran caudal de materiales.

2 Arcipieste de Talavera, pp. 93 y 96.

- Arcipreste de Talavera, p. 93. Iôn Tortosa, a partir de 1279 , el homicidio se enstigaba con la pena de muerte. Véase Brenvienruo Orivin, Codigo de las Costumbics de Tortosa. MIadrid, I876, pp. I31-32 y III, p. 395. 
"Li yo fablé con ella en la carcel c rogué e puse rogadores e clla nunca quiso synon salir por seitencia». Después encientran a su "anigo" - la expresión es del Arcipreste- Fiue sometido a tormento y confesó cl dclito. El amantc huyó de la cárcel y la mujer "fue colgada». Los hechos se complicaron después, porque el verdugo, movido por pasiones drslonestas, profasió el cadáver de la nujer. Essta vez los "rogadores" dicron resultado. Lìl verdugo, en vez de ser castigado con la muerte, fue públicamente azotado. El Arcipreste interpreta la forma de llevarse a cabo el castigo de la mujer cono la aplicación de un juicio de Dios ${ }^{1}$. Estamos ante narraciones semejantes a las que con el nombre de ufazañas" aparecen en algunos textos jurídicos. Cuando las "fazañas" versan sobre delitos, encontramos parecida forma de describir lo concerniente a la conducta de los culpables y a la intervención de la justicia ${ }^{2}$.

No sería muy difícil probar, en este sentido, que las formas de aplicar las penas de mucrte eran conocidas en los lugares citados por el Arcipreste. La muerte cn la horca estaba muy extendida en la Fidad Meclia. Iin cuanto a la hoguera, ann sicnclo un cisitigo excepcional, se solía aplicar en algunos delitos cn los que participaban mujeres. Lis lo que sucedía en 'Tortosa, donde se localiza la correspondicnte narración del $\Lambda$ rcipreste.

Más difícil de explicar resulta la intervención de los "rogadorcs", sobre los cuales no estam us bien informados. Los volveremos a circontrar en algún otro pasaje del Corvacho ${ }^{3}$.

Iin los delitos de mutilación, el relato adquiere características verdaderamente dramáticas. De tal sucrte, que apenas se menciona la intervención de la justicia, al poner todo el peso de la narración en las medidas tomadas por el delincuente. Sabennos que, en uno de los casos, la mujer autora de la mutilación fue interrogada por la antoridad judicial sobre los móviles del delito. Ii Arcipreste recoge las palabras de la mujer, cn las que se refleja hasta qué extrcmo podía llegar cl sentimiento de venganza. Había cortado la lengua de su marido con sus pro-

1 Arcipreste de Talavera, p. 94. El Arcipreste to se olvida cle clar nombres y de consignar las fechas, para ofrecer la narración con tocio detalle.

2 Sobre la forma narrativa que adoptan las fazañas de tipo juridico puede verse nuestro trabajo Fazañas e Historiografta, en Hispania, I972, 32, pp. 6r-76.

3 Código de las Costnmbres de Tortosa. III, p. 348. De la intervención de personas influyentes para decidir la suerte de los procesos - rogadores- tratan alguuos textos castcllanos. Así cl Libro de los Fiteros de Castilla; "e por su rucgo perclonalcs el rey". I'n La Celestina se llegaráa a decir: "O) ne nunca faltan rogradorcs para mitigar las penass", II, 87 . 
pios dientes, solo por haberle visto hablar con otra mujer. Es como si al tomar venganza, se hubiesen aplicado los esquemas del Talión ${ }^{1}$.

La narración se alarga y complica al tratar del ermitaño de Valencia. Una vez más, nuestro autor elige este caso entre otros muchos. Ha procurado acentuar las notas literarias, de las que aquí podemos prescindir. Los hechos ocurrieron en Valencia y fueron muy sonados. La fama de la vida ejemplar del ermitaño había llegado muy lejos. Por supuesto, el buen Arcipreste de Talavera le conocía muy bien, según nos dirá, una vez más: "Yo lo conoci, fablé e comi e bevi con el hermitaño de Valencias ${ }^{2}$. Lo de su santidad era una farsa. No se privaba de nada el falso ermitaño. Bucna casa, comida exquisita y abundante, y mujeres con quienes entretenerse. La intervención de la justicia fue por otras razones. Un pintor presentó una denuncia contra él. Resultó que el ermitaño hacía invocaciones a los diablos. $Y$ para dar más realismo al asunto, encargó a un pintor conocido que le hiciese un cuadro con una represcutación diabólica. Il pintor, cumplido el encargo, sintió remordimientos, y fue a contársclo al gobernador de Valencia.

$Y$ en la casa del ermitaño se presentó el gobernador con nutrido acompañaniento. No hace falta entrar en los detalles de lo que después sucedió. Interesa fijarse en la actuación del gobernador, en la que cabe distinguir dos momentos. Primero, el gobernador trata de comprobar si la denuncia del pintor responde a. la realidad; con tal motivo, se persona en la casa del ermitaño. Se trata de una misión inspectora, al modo de las que cumplen los pesquisidores medievales ${ }^{3}$. I, que el gobernador busca son pruebas de la culpabilidad del ermitaño. En una cámara secreta y bien allajada, que nadie podía imaginar, por lo bien escondida que estaba, encueutra el cuadro con las representaciones diabólicas. En principio no manda recoger el cuadro para usarlo en el juicio. Le basta con tomar testigos entre los acompañantes. Los únicos que pudieron

1 Arcipreste de Talavera, p. 95. En los Bocados de oro se recoge un uexemplon en términos muy parecidos a los de la narración del Corvacho: «E tajó entonces ent'el rrey Rralion el cabo de su lengua con sus dientesн. Ed. KNusr, en Mittheilungen aus dem Eskurial. Tübingen, 1879, p. I22.

2 Arciprestc de Talavera, 12p. 238-43.

- Sobre la pesquisa medieval puede verse el trabajo de JoAQUín CERDÁ, En torno a la pesquisa y procedimicnto inquisitivo en el derecho castellano-leonés de la Edad Media, en AHDE, 1962, 32, pp. 483-517.

Iin cuanto a la intervención del gobernador, podrla explicarse por el hecho de que cn el Reino de Valencia la Gobemación general comprendfa la jurisdicción civil y criminal. Véase Ji:sús LaIINDE, AbADtA, La Gobernación General en la Corona de Aragbn. Madrid, 1962, pp. 394-4I9. 
ver el cuadro fueron los testigos; los demás acompañantes esperaban a la puerta de la casa. A la vista de las prucbas, el gobernador nete en prisión al ermitaño. Aquí termina la primera fase de su actuación. Luego viene el juicio propiamente dicho. El Arcipreste se muestra menos explícito en esta fase. Habla del tormento a que fue sometido el ermitaño, para lograr su confesión, y de la sentencia: muerte en la hoguera. Entre una y otra fase se produce un hecho curioso. La gente sigue creyendo en la santidad del ermitaño. Todas las culpas se las echan al gobernador. Su situación se hace muy difícil; personas importantes de la ciudad "ruegan" por el ermitaño; el gobernador llega a temer por su vida, hasta el extremo de verse obligado a descubrir los términos de su pesquisa, para así calmar a la gente.

Veamos cuál pucde ser la calificación del delito cometido por e! ermitaño. In un lugar el Arcipreste llama «nigromántico» al ermitaño; y en la Edad Media la nigromancia se consideraba un delito. En el caso del ermitaño, el delito cobra sin duda especial resonancia, porque los espíritus que se invocan eran, nada menos, que los diablos. A esto hay que añadir que en cl cuadro se represcntaba "cóno nuestro Scñor cstabar crucificado e el diablo ally pintado muy desonestamente". Todo lo cual hace pensar que el ernitaño pudo ser castigado como hereje, al modo medieval. Por eso la pena que se impuso fue la de la loguera, que los textos medievales aplican a los herejes. A no ser que se considerase que el delito fuesc el de hechicería. Hay un relato sobre cl tema de la liechiccría particularmente intcresante por cl tipo de pena que se aplica. "En Barcelona yo conoscí una que nunca su casa de vaziava de los que venían a estas burlerías, vicja de setenta años. E la vi colgar, a la puerta de uno que mató con ponçoñas por los sobacos, e a otra puerta de otra casada, que muerta avia, la colgaron del pescueço; e después fue quemada al Cañed, fuera de la cibdad, por fechizeria, e non la valió toda quanta favor tenía de muchos caballeros» ${ }^{2}$.

1 Tal era la pena aplicada en territorio valenciano, que es donde ocurrió el suceso. Asi en los Fori Antiqui Valentiae, CXIX, 29 se lee: "Heretici, et sodomitici comburanturn. Ed. MLANUEr, DUALDE SERRANo. Mladrid-Valencia, I950-67, p. 242. Sobre la confiscación de bienes de los herejes, Fori, CXIX, 37. También; Fori Regni Valentiae (Valencia, 1547), fols. 200-206.

En otros lugares sucede lo mismo. Sirva de ejemplo Fuero Real IV, I, i y 2. Id. Codigos Españoles, I, Madrid, 1872, p. 405.

In relación con la nigromancia se dirá en Partidas, VIII,XX IIT, 2: aNegrouantia dicen on latin, a un saber estraño que es para encantar cspiritus malost.

- Arcipreste de Talavera, pp. I72-73. Parcce como si la aplicación conjunta de las dos penas - la de wucrte en la horca y en la hoguera- se debicra al licelio de darse unidos dos delitos, el de homicidio y el de hechicería. El envenenamiento 
Otras veces el Arcipreste recoge "exemplos» de los que tiene noticia indirecta. Hay dos particularmente interesantes, de los que vamos a liablar al mismo tiempo ${ }^{1}$. El tema es la venganza de dos maridos burlados. No acuden a la justicia para castigar el adulterio de sus mujeres, ni se toman tampoco la justicia por su propia mano. I a muerte de sits esposas inficles va a ser planeada con sumo cuidado, para evitar después cualquier sospecha: será algo asi como un "crimen perfecto". Sus mujeres son curiosas y desobedientes; bien lo saben los maridos, que van a sacar partido de $\tan$ notoria debilidad de sus mujeres. Si les prohiben algo, por lo peligroso que pueda ser para sus vidas, a buen seguro que lo harán. Es lo que hacen los maridos, después de haberlo pensado bien. A la una se le advierte que no beba de un recipiente; y a la otra, que no abra un arca. El recipiente contiene vino envenenado. $Y$ en el arca hay una ballesta lista para dispararse. Las mujeres, ausenles los maridos, no pueden vencer la tentación y mueren víctimas de su curiosidad. Como las palabras de sus maridos fueron dichas ante testigos, naulic les inputará la muerte ocurrida.

Interesa destacar lo que pensó uno de los maridos al maquinar la muerte: "Si la mato perdido so; que tiene dos cosas por sy: la justicia e sus parientes, que procederán contra mi. La justicia porque ninguno non deve tomarla por si sin conoscimiento de derecho e legitimos testigos, dignos de fe e buenas provanças, con estrumentos e otras escrituras autenticas e este delante aquel que es por la justicia del rey presiclente e governador, corregidor e regidor e ninguno por si sin non deve tomar venganza, nin punir a otro ningun. E segund esto, pues, Yo de mi syn provançils non lo puedo fazer. Yten mas los parientes que ge lo levante por la matar e me querer con otra de nuevo ayuntar; averlos he por enemigosi" ${ }^{2}$.

Sin duda el Arcipreste, en esta como en otras ocasiones, ha querido hacer gala de sus conocimientos jurídicos. La refinada forma de tomar venganza los maridos se complementa con la condena de la venganza privada, en trance de ser superada, a través de otros procedimientos

cs castigado con la muerte en uno de los textos que rigió en Barcelona, el Liber Judiciortm, VII, 2, 3. F, ZevUMik. Hannover, 1902, p. 259. Por su parte, los lisatges, otra de las fuentes aplicadas en Barcelona, castigan con la hoguera delitos cometidos por mujercs, Lisntges de Barcelona, 95. Id. ABADAI, y VAI,Ls 'NAnIRNI:R. Barcelona, 1913, p. 43. Véase también Usatges 94, para otros delitos ulue puedan llevar consigo la pena de muerte en la horca.

1 Arcipresite de Talaiera, pp. I50-5I.

2 Arcipreste de Talavera, p. I5I. 
juridicos más adecuados ${ }^{1}$. Iin cuanto a los medios de prucba propucstos por el Arcipreste - prucba de testigos y documentos- resultan asinism, muy modernos, como era de esperar en persona formada en el derechs, canónico. Los órganos judiciales, en cambio, adolecen de una cicría confusión. Se lian mezclado en la narración del Arcipreste insíitucionc:s de la Corona de Castilla y Aragón, algunas de las cualcs, al contrario de cómo piense el Arcipreste, no gozaban de jurisdiccićn ${ }^{2}$.

A veces los "exemplos» del Arcipreste proceden del mundo político. Muy conocido es el de David y la mujer de Urías. El Arcipieste lo recuerda para fustigar "el carnal deseo e adulterio, en derecho canónico llamado". $Y$ no se olvida de señalar los problemas políticos que trajo consigo la conducta del rey David ${ }^{3}$.

La crítica del Arcipreste no se deticne, pucs, ante quicnes ostentan el poder. Y así para ver hasta dónde llega la collicia en la mujer, utilizó un "cxemplo" que protagoniza una reina. Ia acción sc situa cu Barcelona ${ }^{4}$. La reina no hacía más que dcclarar que jamás cutregaría su amor a ninguin hombre por mucho que le ofrecicran. Ni por joyas, ni ciudades; ni siquicra por el rcino de Castilla. Les lo que contcsta a un caballero que vino a tratar del tema. Mas cuando el caballcro pregunta por su actitud en caso de que el ofrecimiento consisticse en ser "cniperadoral de todo el mundo, la reina vacila. Su firmeza inicial ha de:aparecido. El punto débil de la ambición ha quedado el descubierio. $\mathrm{Y}$ eso que se trataba, según confiesa el Arcipreste, de una reina muy honesta. Con este "exemplo" ha sabido expresar el Arcipreste la fuerza de la ambición política, desde el ángulo femenino. Y resulta curiosa lo. forma de comparar el reino de Castilla, que para muchos hispanos cra el más grande y poderoso, con el "Imperio del mundo".

Algunas otras observaciones de tipo político surgen en el Corvactio aquí y allá. Se trata, por lo general, de máximas y tópicos de muy varia procedencia. Los temas son los consabidos: el papel que juega la pro-

1 ANger I,óplz Aro, El Derecho Penal Español de la Baja Edad Media. en $A H D E$, 1956, 26, pp. 354-9. La venganza privada, sin embargo, se manturo vigente a lo largo de la Modenidad, como ha señalado Fruncisco TOMLis VALUiNTE en su obra El Derecho Penal de la Monarquia Absoluta. Madrid, i969, pp. 46-80.

2 Asi por ejemplo el Arcipreste habla de corregidores en Valencia, cuando sólo existen en Lcón y Castilla. Los términos, presidente y regidor, quedan un tanto inprecisos.

3. Arcipresic de Talatera, pp. 78-80.

- Arcipresle de Talavera, pp. I21-3. 
vikencia en el mundo político, la forma de distinguir al buen rey, el cuidado que hay que poner en el trato con los poderosos, o la igualación finel causada por la muerte, que no respeta dignidades políticas por altas (qui scan. No faltan lass notas criticas, como cuando se fustiga duramente la afición de los diversos estamentos por llegar a los pucstos más altos, hasti el extrcmo de desear la muerte de las demás personas con tal de ocupar alguna vacante ${ }^{1}$.

I a serie de males y fallos del mundo juridico denunciados por el Arcipreste se corresponden con las advertencias sobre la virtud de la justicia. También en este aspecto la situación es bien triste. No se respetan los derechos ajenos. No hay temor a la justicia. $Y$ no sólo por parte de los distintos grupos de población. El mal ha penetrado en los mismos que la administran. A tal grado ha llegado la situación, que, segín el Arcipreste, está muy cerca el fin del mundo. "Ved señores, los que esto lees, que oystes, vistes, entendes, que vos paresce como se acerea la fin del mundo, pucs non es temido Dios ni su justician." Pocos piensan en la "piadosa justicia» divina; sólo temen el castigo que puedan recibir aquí en la ticra, por los delitos cometidos ${ }^{2}$.

Tanta invocación a la justicia, termina por proyectarse en una definición: "Justicia sea dar a cada uno lo que suyo es». Se trata de la conocida definición de justicia, procedente del Derecho romano que tantas veces encontramos en la Baja Edad Media castellana ${ }^{3}$. El Arcipreste

1 Arcifreste de Talatcra, pp. I 41, 220, 247 y 268. En breves fómulas se recogen principios politicos, como por ejemplo: aquel es digno de ser llamado rey quic rç̣ir salic sus regnos" (p. 220). İl Arcipreste atribuye el principio a Catón. Sin cmbrigo. lenma - a quien sigte González Muela- no ha encontrado cl texto correspondicnte en les Dicta Catonis. Is claro que se trata de un principio pertenciente a la tradicionn isidoriana.

A S. Agrustin es atribuido otro principio político que viene a decir: "Porque al sobcrino asi placen. Se trata, naturalmente, de una de las versiones del tan conociù "quod principi placuit", que encontró en la época del Arcipreste amplia difusión, por obra de la llamada recepción del Derecho romauo. En los textos normativos valencianos se repite una clólusula parecida: "Plau a sa Magestad que". Asi en Fori Regni Valentiae, passinn.

2 Arcipreste de Talavera, p. 234. Tin la Baja Edad Media es frecuente la deuuncia de los malcs en la administración de la justicia, como harán Pedro López de Ayala, Juan de Mena o el autor de las Coplas do Mingo Revulgo, por citar ejemplos muy conocidos.

- Arcipreste de Talavera, p. II . Algunos otros ejemplos de definición pueden verse en nucstro trabajo, Ideales poltticos de Juan de Mera, en Revista de Estudios Politicos, 1973, 188, pp. 159-60. Il propio Arcipreste de Talavera en su I'illa de Sant Isidoro recoge dl siguiente párafo: 'Tiú scrás juez e testigo quando vinicres al juycio a dar a calla "no gnalardon segund que fizon. nid. Clísicos Castellancs. MLadrid, 1952, p. roy. 
llega a esa definición al tratar del delito de hurto, que también define, en forma bien moderna, por cierto: "pues furto es dicho tomar el ombre - usurpar o contractar la cosa agena contra voluntad de su señor».

In el juicio final se manificsta la justicia divina en toda su plenitud. Iil $\Lambda$ rcipreste emplea el simbolismo tradicional llevado a curiosos extremus. Dios es el juez; el diablo actúa como "demandante»; el alma scrá "cl reo defendyente"; abogados, la Virgen, los santos y ángeles del paraíso; por parte del Diablo hacen de abogados los componentes de la "corte infernal». El Angel de la guarda será el procurador. Habrá testigos, naturalmente. De un lado, Dios, el ángel y "su conciencia»; y del otro, las malas obras. "El proceso del ánima será la vida e el tiempo como lo gastón; de notario actuará el mundo entero. La sentencia será eterna; 110 habrá apelación de ninguna clase ${ }^{2}$.

Ein una línea semejante de simbología juridica se expone, en muy breves palabras, la leyenda de un pacto con el diablo. No hay en la leyenda la riqueza de detalles del milagro de 'reófilo que cuenta Berceo. Un-hombre toma al "diablo por scñor». El pacto se celebra por causa de una mujer. Cabe destacar el simbolismo de la carta: aquí también el pacto con el diablo queda reflejado en un documento, que, luego, a ruegos de un santo, se terminará por recuperar ${ }^{3}$.

Parecida simbología se utiliza en el enfrentamiento habido entre dos figuras conocidas de la época: fortuna y pobreza. El tema es tratado con detenimiento 4 . La pobreza se ha encontrado en uno de sus recorridos con la fortuna. Discuten; no se ponen de acuerdo; y terminan envueitas en un proceso. Con la curiosa particulariclad de que quien dicta sentencia va a ser una de las partes: la pobreza. Es como si la pobreza hubiera sido converticla en juez. Interesa reparar en la sentencia.

E1 Arciprestc ha cuidado las formas jurídicas al redactar la sentencia.

1 Arcipreste de Talaüìa, jo. III. Is una definición semejante a la que darán algunos tratadistas de cuestiones penales de época posterior. Sirva de ejemplo Jost BERnf, Práctica Criminal (Valencia, 1765): "Hurto consiste en tomar cosa agena con ánimo de hacerla propia, sin conseutimiento del señor". "or su parte Pradilin Darnumo dirá en la Suma de todas las leyes Perrales: "el que toma la cosa ajena sin voluntad de su dueñon. Madrid, 1627, p. 20. En términos semejantes se expresa nuestro Código Penal, art. 514: «Son ros de hurto: $1 .^{\circ}$ Los que con ánimo de lucrarse y sin violencia o intimidación en las personas ni fuerza en las cosas toman las cosas muebles ajenas sin la voluntad de su dueñon.

2 Arcipreste de Talavera, p. Ir5. Resumen y comentario del proceso en $\mathrm{NI}$ Crito AICAI, ZAMORA, Nuevas eslampas procesales de la literatuia española, paginas $322-25$.

- Arcipreste de Talavera, 1). 67.

- Arcipreste de Talavera, pp. 252-7I. 
Conienza, con una invocación; siguen los fundamentos de hecho, en párrafos separados, con el tradicional encabezamiento del "Visto»; viene, luego, la resolución, que comienza así: "Fallo: que la devo condepnar e condepno". $Y$ termina: "E por mi sentencia definitiva e por syempre jamas asy la pronuncio en estos e por estos escritos». Se hacen, al final, las correspondientes indicaciones sobre fecha, lugar y reinado, con diversos añadidos en tono fantástico.

La sentencia fue "rezada, leyda, e publicada" por el juez. Quedó la fortuna conforme con el fallo; no utilizaría la vía de apelación. Bien claro lo dijo "que la quería complir e guardar por syempre, segund. que en ella de verbum ad verbum se contenía. La pobreza fue condenada a prisión "en cadenas». Las operaciones de ejecución de la sentencia son descritas brevemente. Corren a cargo del juez. En el proceso no se pagaron costas?.

Ha sabido cuidar las formas nuestro Arcipreste, como hiciese en ticmpos su colega, el Arcipreste de Hita, en la sentencia de don Simio, Alcalde de Buxia. Con la diferencia de que en la sentencia de la pobreza no se planitean los dificilísimos problemas jurídicos de las excepciones dilatorias y perentorias en las que se vio envuelto don Simio. Si descontamos algunos aspectos de la invocación, los añadidós fantásticos en torno a la data y el marco alegórico, la sentencia podría pasar, "mutatis mutandis", por una de la época.

Algunos ejemplos bastarán para probarlo. Era práctica frecuente fundamentar la sentencia a base de consideraciones, que iban precedidas por la palabra «visto». In cuanto a la expresión "fallo que», la podemos encontrar en muy diversos lugares, al modo de una cláusula de estilo ${ }^{2}$. $\mathrm{Y}$ aún cabe hacer algunas comparaciones más precisas: habrá sentencias en las que se rer.ogerán expresiones como éstas: "e por mi sentencia definitiva judgando lo pronuncio»; "e por esta nuestra sentencia definitiva asi lo declaramos»; "It judgando por sentencia definitiva pronunciolo" ${ }^{3}$. Términos todos ellos muy semejantes a los empleados en el Corvacho, como acabamos de ver.

1 Ia sentencia puede verse en Arcipreste de Talavera, pp. 270-7x.

- Ejenplos de sentencias en Privilegios, Escrituras y Bulas de la insigrze $y$ real Iglesia colegial de Santillana, II. Santander, 1926, pp. 284, 333, 337; FRANcisco CaNTERA BuRgos, Aliar Garcia de Santa Marla. Madrid, 1952, p. 30.

- Ios textos pueden verse en Privilegios, Escrituras y Bulas de la insigne y real Iglesia colegial de Sastillana. p. 287; Coleccibn Diplomática de Cuellar. Segovia, 1961, pp. 514-S, y Doctimentos del Archivo General de la Villa de Madrid. İd. Tmotio Domingo Panacio, II. Madrid, 1888, p. 287. 
Sucede, además, que en la propia época cabe encontrar en obras literarias análogas maneras de figuración procesal. La justicia, la pobreza y un buen número de figuras alegóricas, intervienen en pleitos, que suelen decidirse por sentencia. Tal sucede en el Cancionero de Baena con un largo proceso en el que participan, en calidad de partes, la soberbia y la mesura. Con muy buena lógica, le toca dictar sentencia en esta ocasión a la justicia, que, como las demás figuras ideales, aparece representada como una doncella. No faltan en la sentencia las consabidas expresiones del "visto" $y$ "fallo que»" Más breve resulta otro proceso en el que aparece en calidad de parte la pobreza, que obtendrá sentencia favorable ${ }^{2}$. En la literatura de finales de la Edad Media hay todo un ambiente de alegoría jurídica que llega hasta nuestro Arciprestc ${ }^{3}$.

Otras veces el Arcipreste hace interesantes referencias a temas jurídicos relacionados con el matrimonio y la filiación. Es natural que así sea, dada la indole de su obra. Basado en consideraciones, que pudiéramos. calificar de sociológicas, distingue cuatro tipos de matrimonio. De los cuatro sólo considera adecuados los celebrados entre personas de una misma edad; los demás traen consigo muchos inconvenientes. Es interesante lo que dice con respecto a los requisitos del matrimonio: "Comiénzase con los esposorios, firmase con las palabras, después consúmase e acábase en la carnal cópular. Por las fechas en que escribe el Arcipreste, el requisito de la consumación del matrimonio se había extendido ya ampliamente en el derecho de la Iglesia 4

Resultan muy interesantes otros datos que recoge sobre el matrimonio: "Tomo nombre - segund dize Ostiense en la Suma en este títuloque se compone de madre e mumio, que quiere dezir oficio de madre. Otros dizen, asy como el Sacgramental en este título, en el párrafo Qué cosa es matrimonio, dize que se compone de madre e munir, que quiere dezir guarnescer, porque guarnesce e guarda la madre de ynfamia e fornicación.

Otros dizen que tomó nombre de monos, que quiere dezir $\imath$ no, porque de la materia de dos se engendra uno. Sant Esidro en el libro De las

1 Claro está que en sentido estricto, la ksentencia” del Corvacho no seria una verdadera sentencia, por ser la Pobreza juez y parte, al mismo tiempo, y por utilizarse la coacción en los medios de prueba. Véase Nicrito AICAIrd ZuMora, Nuevas Estampas procesales de la Literatura española, pp. 326-27.

- Cancionero de Juan Alfonso de Baena, II, pp. 6ro-23.

- Ya Huizinga destacó la importancia que aún tenia la simbologia a fines de la Edad Media. Madrid, 1967, pp. 3×4-55. Sobre la alegoria juridica, GARCiA Par, Yyo, Del mito y de la razón de Estado en el pensamiento polltico. Madrid, 1967.

- Arcipreste de Talavera, p. 203. 
ethimologias, dize que tomó nombre matrimonio de matrona, que quiere dezir madre del nascido" ${ }^{2}$.

En una ocasión se refiere al llamado matrimonio a juras, con o sin testigos. Los juramentos en que se basaban esos matrimonios, según el Arciprestc, cran quebrantados con mucha facilidad ${ }^{2}$.

In cuanto a la filiación, los datos que ofrecen prueban la precaria situación de los hijos ilegítimos. Todo el mundo les consideraba muy mal; no podian recibir herencia paterna, ni alcanzar shonras temporales». Y sólo, en caso de ser legitimados, se les permitía optar a un beneficio eclesiástico ${ }^{3}$.

Pasemos al tema de las fuentes. No suele el Arcipreste apoyarse en obras de derecho al ofrecer datos jurídicos. Le basta, al parecer, con su propia experiencia, o con el manejo de principios y definiciones, que tal vez, por el alto grado de difusión a que han llegado, no precisasen de la cita exacta. En cualquier caso, cuando aparecen las citas es en cucstiones de tipo moral, religioso o doctrinal; rara vez en cuestiones estrictamente juridicas. $Y$, cuando esto sucede, no es para extraer de la obra citada una norma o algún principio jurídico, sino para comprobar el grado de difusion de un delito.

Entre los temas planteados con apoyo de obras juridicas, destaca el de la predestinación, tan traído y llevado ya en la Baja Edad Media. El Arcipreste dedica al tema muchas páginas, con un cierto acopio de doctrina. San Agustín es una de las fuentes principales. Y a San Agustín en más de una ocasión citará nuestro autor en forma indirecta, a través de textos del Decreto de Graciano. Diríase que los textos que mejor conoce de todos los que cita son los del Derecho Canónico: Decreto, Decretales y Clementinas. Textos muy conocidos de otros autores castellanos de la Baja Edad Media 4.

1 Arcipreste de Talavera, p. 200. En relación con la primera de las explicaciones, puede verse lo que dice el profesor IAI,INDE ABADEA, Iniciación historica al derecho español. Barcelona. 1970, p. 592.

2 Arcipreste de Talavera, p. 89.

3 Arcipreste de Talavera, p. 7o. Ios datos que ofrece Martinez de Toledo concuerdan con los principios de nuestro derecho histórico, tal como puede verse en los trabajos de ENRIQUE GACTO, La filiacion no legitima en el Derecho histórico español. Sevilla, 1969, y La filiación ilegitima en la historia del Derecho Español, $A H D E$, 1971, 41, pp. 899-944.

- Arcipreste de Talavera, pp. 72, 168, 187, 195, 213, 215, 232, 245, 256-7. Entre los muchos autores que recogen citas canónicas recordemos al Arcipreste de Hita. Sobre el tema pucde verse nuestro trabajo, El saber jurtdico del Arcipreste, en Actas del I Congreso Internacional sobre el Arcipresie de Hita. Barcelona, 1973, pp. 409-4 5 . 
Su familiaridad con los textos canónicos se comprueba por la forma que tiene de hacer las citas. Parece como si el Arcipreste estuviese pendiente de las posibles comprobaciones del lector. Cuando el pasaje pucda resultar difícil de localizar - dada la extrema dificultad de los textos canónicos-, las referencias son nuy precisas. Sólo se aligeran las citas si los textos citados quedan al comienzo o al final de las obras canónicas, lo que ocurre más de una vez, no sabemos si por curiosa coincidencia. $\mathrm{Y}$ pudiera ser que, en algún caso el Arcipreste, fiado en su buen conocimiento de los textos, citase de memoria. Así se explicaría alguna falta de correspondencia de sus citas.

Al lado de las obras canónicas propiamente normativas figura en el Corvacho una interesante lista de Canonistas ${ }^{1}$. Todos ellos se incluyen en una relación más amplia, donde aparecen junto a otros nombres muy famosos de filósofos, poẹtas y eclesiásticos. Ia lista, en lo que se refiere a «los maestros en leyes e canones», no ha sido bien interpretada, tal vez por la forma concisa de insertar los nombres de los personajes, sin apenas referencias. Sirva de ejemplo lo que ha sucedido con Juan Andrés, uno de los grandes juristas del momento. Los editores del Corvacho, a pesar de ser excelentes especialistas, han hecho de Juan Andrés dos personajes diferentes: Juan y Andrés ${ }^{2}$. Que Juan Andrés era conocido en Castilla, como jurista, se comprueba con sólo recordar la pragmática de Juan II de I427, en que su nombre figuraba nada menos que al lado del gran jurista Bartolo. En la pragmática, cono es sabido, se dispone que sólo podían ser citados ante los tribunales los juristas anteriores a Bartolo y Juan Andrés ${ }^{3}$. En la lista del Arcipreste hay otros nombres que no ofrecen duda. Inocencio es, claro está, el Papa Inocencio IV, cuyas obras jurídicas fueron muy conocidas; su nombre figura, por ejemplo, en el Libro de buen Amor ${ }^{4}$. Alberrico sería Alberico de Rosate. Y Guillermo, parece ser Guillermo Durante. En cuanto a Juan monje y Juan de Dios, no hay ninguna duda en su identificación como canonistas ${ }^{5}$. Dificultades ofrecen los nombres de Bernardo y

1 Arcipreste de Talavera, p. $26 \mathrm{r}$.

2 En la edición de González Muela aparecen los nombres del canonista separados por una coma, cual si se tratara de dos personajes distintos, Juan y Andrés.

3 La pragmática fue publicada por MIGUEL ANGEl, PÉREZ DE LA CANAL, La Pragndítica de Juan II, de 8 de febrero de I427, en $A H D E$, I956, 26, pp. 659-9o.

- Sobre Alberico de Rosate puede verse CaI.Asso, Medioevo del Diritto. Milán, I954, pp. 579-80. Es menos probable que Martinez de Toledo se refiera a otro jurista del mismo nombre, Alberico di Porta Ravenate, que fue uno de los más famosos glosadores. Véase CArassso, Medioevo del Diritlo, p. 368.

- Sobre Juan Monje y Juan de Dios puede verse, In BrAs, Hisloire du Droit et des Institutions de l'Eglise en Occident VII. Paris, I965, pp. 321 y 326-7. 
Ricardo. El primero puede ser Bernardo Compostelano, que escribió una Suma bastante conocida ${ }^{1}$. Tal vez algún otro nombre de la lista. pueda ser entendido como el de un jurista. En cualquier caso, no sabemos. si nuestro autor tuviese conociniento directo de las obras de esos autores. İra práctica frecuente, aun entre los juristas más especializados, citar sus fuentes de segunda mano ${ }^{2}$. Sea como fuere, no todos los nombres que cita nuestro autor gozaban de notoriedad. En la lista no figura el nombre del Hostiense, bien conocido en Castilla, y en su día citado por el Arcipreste de Hita. Donde aparece, tal como hemos visto, es en otro pasaje del Corvacho, cuando se intenta aclarar el significado. del matrimonio, a la manera que venia siendo habitual en algunas obras de derecho ${ }^{3}$.

En suma, estamos ante un escritor, que hace gala en cada momento. de sus conocimientos jurídicos. El título de bachiller en decretos, que cxhibe en el prólogo, parece habérselo tomado muy en serio. Buena. prucba de cllo son los principios jurídicos, las citas de juristas o las referencias a la administración que van saliendo a lo largo de sus obras. Podia haber prescindido de muchos de esos materiales, sin que el tenorde la obra se resintiera. Al no hacerlo así, es como si hubiese querido. dejar constancia de su buena formación jurídica.

Una formación que se manifiesta en forma bien distinta a la de aque-llos juristas de profesión que llenan sus obras de opiniones ajenas, cuantasmás mejor. Leer a uno de tales juristas no es nada grato.

Nuestro Arcipreste, como gran prosista que es, ha sabido manejar los datos que atañen al derecho. Es lo mismo que harán, con desigual fortuna, algunos escritores hispanos, de finales de la Edad Media, cuya. base de su formación fue el derecho.

Alfonso Martínez de Toledo añade a la formación académica de los. autores su interesante aportación personal. Las situaciones en las que se ha visto envuelto, por lo que se desprende de sus resúmenes, fueron. de una intensidad y hasta de un dramatismo dificiles de igualar.

1 LE BRAs, Histoire dis Droit et des Irstitutions de l'Eglise VII, pp. 314-15-

- Garcfa Garlo, Manual de Historia del Derecho Español. I. Madrid, I967. p. 460 .

3 Ein otras obras del ARCIPRESTE DE TALAVERA aparecen recogidos diversos. datos de interés jurdico, Vida de S. Ildefonso y S. Isidoro. Ed. Clísicos Custellanos. Mradrid, 1952, pp. $34,35,45,67,68,77,78,93$, I01, 109, 132, 135-38 у 148. 
RFE, LVII, 1974.5 LA FORMACIÓN JURf́dICA DEL ARCIPRESTE DE...

Se vive en aquella sociedad al borde de la violencia, entre venganzas crucles y crimenes pasionales. Los apuntes que trazó el Arcipreste de 'Talavera son de un valor inapreciable. Al liacer una exposición del mundo jurídico de la época, el nombre del insigne Arcipreste no deberia olviclarse.

José Luis Bermejo Cabrero 